\title{
Behçet's disease diagnosed by pregnancy-exacerbated genital ulcers
}

\author{
Nobuyuki Kikuchi, Takako Miura, Toshiyuki Yamamoto
}

Department of Dermatology, Fukushima Medical University, Public university in Fukushima, Japan

Corresponding author: Prof. Toshiyuki Yamamoto, E-mail: toyamade@fmu.ac.jp

Sir,

A 35-year-old female visited our hospital, complaining of painful lesions on the lower extremities. She denied prior sore throat or upper airway infection. Physical examination showed a few tender, subcutaneous nodules with redness on the surface of the bilateral lower legs (Fig. la). Pyrexia, joint pain and mucous lesions were not observed. Laboratory data showed an increased level of C-reactive protein (CRP) $(1.57 \mathrm{mg} / \mathrm{dl})$, but were otherwise normal. Histological examination revealed septal panniculitis showing infiltration of neutrophils and mononuclear cells in the dermis and subcutaneous tissues (Figs. lb and c). Vasculitis was not observed. This was the first time that she had developed painful subcutaneous nodules, and she denied both frequent oral aphthae and previous history of genital ulcer. One year later, she became pregnant for the first time and visited our department complaining of genital ulcers at the week 31 of pregnancy (Fig. 2a). A biopsy specimen taken from her ulcerative labia majora showed a number of neutrophils throughout the dermis (Fig. 2b). Laboratory examination showed elevated levels of white blood cell counts $(11,000 / \mu \mathrm{l})$ and C-reactive protein $(0.99 \mathrm{mg} / \mathrm{dl})$. Serum $\mathrm{IgD}$ was elevated $(27.5 \mathrm{mg} / \mathrm{dl}$, normal <9.0). Liver and renal functions were normal, and anti-nuclear antibodies, anti-SS-A, and anti-SS-B antibodies were all negative. Results of the phthalmological examination were normal.

The present case initially developed erythema nodosum, and one year later, during pregnancy, she developed genital ulcers and was diagnosed with incomplete type Behçet's disease (BD). The influence of pregnancy on $\mathrm{BD}$ is controversial. In some cases, remissions or no significant influences have been reported [1-3], while exacerbation of $\mathrm{BD}$ has been reported in other cases [4-6]. In cases of worsening BD, mucocutaneous ulcerations seem to predominate during the second and third trimesters of pregnancy [3,5]. Consistent with this, our case also developed genital ulcers during the late phase of her first pregnancy.

Although pregnancy does not affect the natural development of BD in general, in an analysis of six reviews series, $\mathrm{BD}$ flares occurred in about $30 \%$ of the pregnancies, [3]. The main symptoms during BD flares were oral ulceration $(58.3 \%)$, and genital ulceration $(44.4 \%)$, followed by skin lesions $(25 \%)$ and ocular inflammation (5.6\%). In a case series of 44 pregnancies in patients with $\mathrm{BD}$, remission was observed in more than half of the patients, whereas exacerbation was seen in 12 pregnancies (27.3\%) [2]. Oral ulcers were the most frequently reported symptom that increased in intensity and severity, but other signs such as genital ulcers, eye

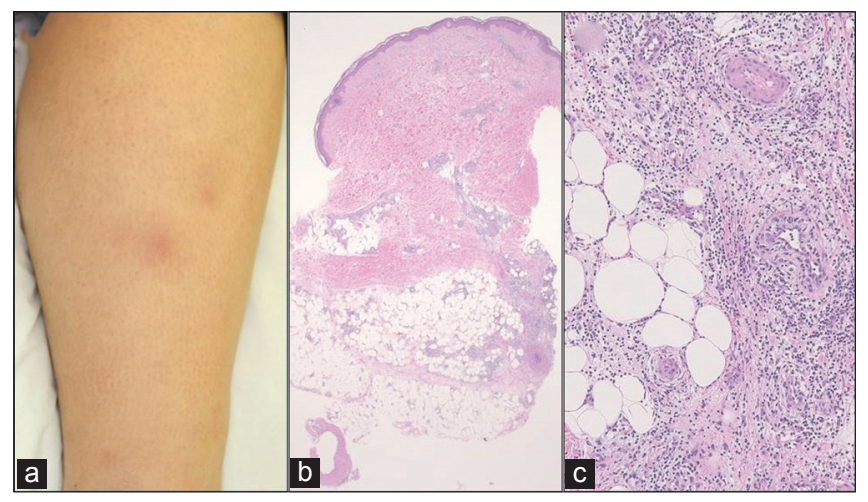

Figure 1: (a) Tender, erythematous subcutaneous nodules on the lower leg. (b) Histological features showing lobular panniculitis. (c) Higher magnification showing dense infiltration of the mononuclear cells and neutrophils. 


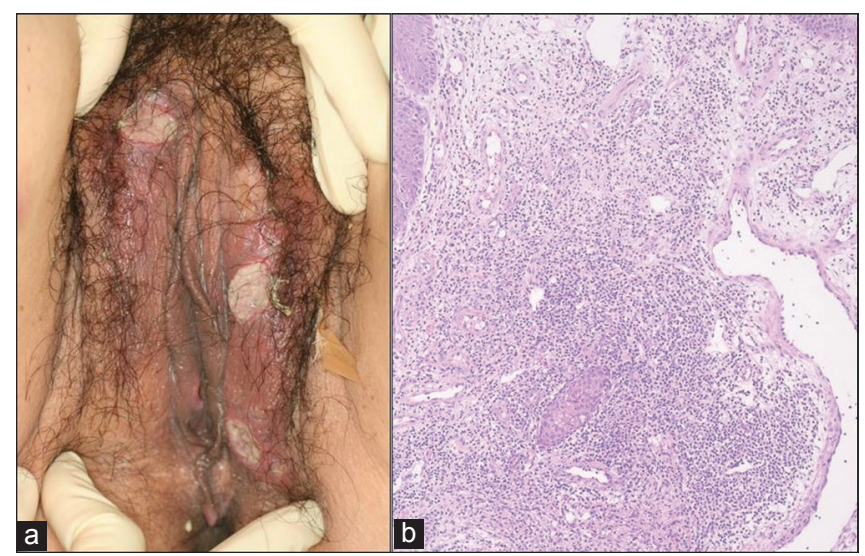

Figure 2: (a) Multiple painful ulcers on the labia majora. (b) Histological features showing numerous neutrophil infiltration throughout the dermis.

inflammation and arthritis have also been reported. In another series of 16 cases, the number of worsening BD during pregnancy was greater than remission [6]. In the same series, deep and frequent genital ulcers were most frequently observed $(n=7)$, and one patient was diagnosed with BD during pregnancy, like our case. Similar to our case, a previous report showed a case with vaginal ulcers appearing during pregnancy, which healed immediately after delivery, suggesting the effects of progesterone withdrawal [5]. BD has been considered to show a Thl-polarized response. Many studies have suggested a predominant Th2-type immunity during pregnancy. Thus, pregnancy-induced immune conditions may inhibit a Thl-shifted imbalance [7], which may generally lead to remission in $\mathrm{BD}$. On the other hand, tumor necrosis factor- $\alpha(\mathrm{TNF}-\alpha)$ increases with pregnancy development, which may contribute to the amelioration of BD. Furthermore, interleukin-10 (IL-10) production decreases in the third trimesters of pregnancy, resulting in an increase in the concentrations of inflammatory cytokines [8]. Taken together, the effects of pregnancy on the activity of BD are various, and differ depending on each individual case.

\section{Consent}

The examination of the patient was conducted according to the Declaration of Helsinki principles.

\section{REFERENCES}

1. Jadaon J, Shushan A, Ezra Y, Sela H, Ozcan C, Rojansky N. Behçet's disease and pregnancy. Acta Obstet Gynecol Scand. 2005;84:939-44.

2. Uzun S, Alpsoy E, Durdu M, Akman A. The clinical course of Behçet's disease in pregnancy: a retrospective analysis and review of the literature. J Dermatol. 2003;30:499-502.

3. Noel N, Wechsler B, Nizard J, Costedoat-Chalumeau N, Boutin du LT, Dommergues M, et al. Behçet's disease and pregnancy. Arthritis Rheum. 2013;65:2450-6.

4. Ben-Chetrit E. Behçet's syndrome and pregnancy: course of the disease and pregnancy outcome. Clin Exp Rheumatol. 2014;32:S93-8.

5. Farrag OA, Al-Sulciman SA, Bella H, Al-Omari H. Behçet's disease in pregnancy. Aust NZ J Obstet Gynecol. 1987;27:161-3.

6. Gül Ü. Pregnancy and Behçet's disease. Arch Dermatol. 2000;136:1063-4.

7. Saito S, Nakashima A, Shima T, Ito M. Th1/Th2/Th17 and regulatory T-cell paradigm in pregnancy. Am J Rep Immunol. 2010;63:601-10.

8. Moreli JB, Ruocco AMC, Vernini JM, Rudge MVC, Calderon IMP. Interleukin 10 and tumor necrosis factor-alpha in pregnancy: aspects of interest in clinical obstetrics. ISRN Obstet Gynecol. 2012;2012:230742.

Copyright by Nobuyuki Kikuchi, et al. This is an open-access article distributed under the terms of the Creative Commons Attribution License, which permits unrestricted use, distribution, and reproduction in any medium, provided the original author and source are credited.

Source of Support: Nil, Conflict of Interest: None declared. 